\title{
Pengembangan Umkm Kerajinan Anyaman Untuk Meningkatkan Perekonomian Masyarakat Desa Sumberjo Kecamatan Sarirejo Kabupaten Lamongan
}

\author{
Yenni Vera Fibriyanti, S.E., M.Akt ${ }^{1}$, Noer Rafikah Zulyanti, S.Sos., MA $^{2}$, Alfiani ${ }^{3}$ \\ Prodi Akuntansi, Fakultas Ekonomi, Universitas Islam Lamongan \\ E-mail:yennivera58@gmail.com,rafikahalie@gmail.com,alfiani1902@gmail.com
}

\begin{abstract}
ABSTRAK
Pembuatan kerajinan anyaman di Desa Sumberjo, Kecamatan Lamongan, Kabupaten Lamongan mempunyai peran dalam meningkatkan perekonomian masyarakat. Namun di sisi lain, terdapat permasalahan dalam mengembangkannya yaitu kurangnya keterampilan dan ketelatenan dalam membuat kerajinan anyaman. Masyarakat Desa Sumberjo banyak yang berprofesi sebagai petani atau buruh tani. Demikian pula dengan pemuda Desa Sumberjo, mereka banyak memilih bekerja di luar kota. Penelitian ini menggunakan metode kualitatif yang ditekankan pada jenis deskriptif kualitatif. Teknik pengumpulan data yang digunakan adalah focus group discussion. Hasil yang telah dicapai dalam pelaksanaan pelatihan pengembangan UMKM kerajinan anyaman yaitu (1) meningkatnyaketrampilan pengrajin anyaman dalam membuat produk anyaman bambu dan anyaman tikar; (2) meningkatnya daya saing produksi kerajinan anyaman; (3) meningkatnya perekonomian masyarakat Desa Sumberjo, Kecamatan Sarirejo, Kabupaten Lamongan melalui pembuatan laporan keuangan UMKM.
\end{abstract}

Kata Kunci:kerajinan anyaman, UMKM, peningkatan perekonomian

\section{PENDAHULUAN}

Desa Sumberjo merupakan salah satu desa di Kecamatan Sarirejo Kabupaten Lamongan. Secara geografis Desa Sumberjo terletak pada posisi $.6^{\circ} 51 .^{\prime}-7^{\circ} .23^{\prime}$ Lintang Selatan dan

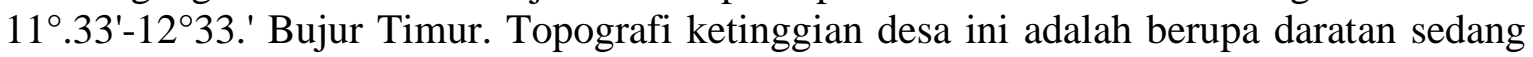
yaitu sekitar 13 meter di atas permukaan air laut. Berdasarkan data dari BPS, masyarakat Desa Sumberjo yang bekerja di sektor pertanian berjumlah 939 orang, yang bekerja disektor jasa berjumlah 178 orang, yang bekerja di sektor industri 276 orang, dan bekerja di sektor lain-lain 318 orang. Dengan demikian jumlah penduduk yang mempunyai mata pencaharian berjumlah 1.711 orang. Secara umum mata pencaharian warga masyarakat Desa Sumberjo dapat teridentifikasi ke dalam beberapa sektor yaitu pertanian, jasa/perdagangan, industri dan lain-lain.

Desa Sumberjo mempunyai potensi yang dapat dikembangkan untuk meningkatkan perekonomian masyarakat yaitu kerajinan anyaman. Kerajinan anyaman yang ada di Desa Sumberjo merupakan wujud budaya yang ditinggalkan secara turun-temurun. Kerajinan anyaman ini berbahan dasar dari bambu yang diubah menjadi sebuah karya tangan dengan nilai estetika yang ternilai harganya diitangan orang-orang yang terampil dan kreatif. Kerajinan tangan anyaman bambu ini adalah hasil olahan dari bambu yang sudah kering kemudian diolah menjadi benda yang memiliki nilai jual.Kerajinan tangan anyaman bambu ini merupakan kegiatan wirausaha dari UMKM masyarakat Desa Sumberejo.

Potensi kerajinan dari bambu yang ada di daerah Desa Sumberjo Kecamatan Sarirejo Kabupaten Lamongan ini dimanfaatkan oleh masyarakat menjanjikan keuntungan yang 
besar karena mempunyai nilai ekonomis tinggi. Salah satu hasil kreatifitas dan keterampilan masyarakat Desa Sumberjo Kecamatan Sarirejo Kabupaten Lamongan yang berasal dari tanaman bambu tersebut adalahkeranjang ikan (Tembres). Hasil penjualan dari tembres dapat menyumbang peningkatkan perekonomian masyarakat Desa Sumberjo. Menurut Yudha (2017), peningkatan perekonomian adalah suatu perubahan jenjang atau perbaikan kondisi dari perekonomian yang lemah ke arah perekonomian yang lebih baik atau mengalami kemajuan dari sebelumnya.

Berdasarkan data BPS (2003), populasi usaha mikro kecil dan menengah (UMKM) jumlahnya mencapai 42,5 juta unit atau 99,9 persen dari keseluruhan pelaku bisnis di tanah air. UMKM memberikan kontribusi yang signifikan terhadap penyerapan tenaga kerja, yaitu sebesar 99,6 persen. Sementara itu, kontribusi UMKM terhadap Produk Domestik Bruto (PDB) sebesar 56,7 persen. Angka tersebut terus meningkat seiring dengan pertumbuhan UKM dari tahun ke tahun. Usaha Mikro Kecil Menengah (UMKM) memiliki peran yang strategis dalam pembangunan ekonomi nasional. Pemberdayaan UMKM di tengah arus globalisasi dan tingginya persaingan membuat UMKM harus mampu menghadapi tantangan global.

Selain itu, masyarakat Desa Sumberjo juga berprofesi sebagai pengrajin anyaman tikar dari tali rafia. Warga pengrajin tikar ini biasanya bisa menghasilkan 2 sampai 3 buah tikar setiap minggunya. Kreatifitas ini sangat diperlukan dan harus ditingkatkan lagi agar dapat menambah penghasilan warga masyarakat Sumberjo melalui UMKM kerajinan anyaman

Kerajinan tikar anyaman dari tali rafia ini tidak hanya dipasarkan di dalam negeri, tapi juga sudah merambah ke beberapa negara tetangga, seperti Malaysia dan Taiwan. Produk anyaman tikar Desa Sumberjo, Kecamatan Sarirejo, Kabupaten Lamongan juga sudah menyebar ke seluruh Indonesia.Saat iniadatiga ukuran tikar lipat, yakni ukuran 2x3 meter, ukuran $2 \times 2$ meter, dan ukuran $2 \times 1$ meter. Satulembartikarukuran $2 \times 3$ meter membutuhkan bahan baku sekitar $20 \mathrm{~kg}$ tali rafia.Untukmembuattikarlipatini memang membutuhkan ketrampilan dan ketelitian. Seorang pekerja membutuhkan waktu sekitar empat hari untuk menyelesaikan tikar lipat berukuran $2 \times 3$ meter. Proses menganyam akan lebih cepat jika pekerja benar-benar sudah terampil dan ahli. "Semakin sering mencoba, semakin cepat pengerjaannya,".

Kerajinan adalah suatu usaha yang dilakukan secara terus menerus dengan penuh semangat ketekunan, kecekatan, kegigihan, berdedikasi tinggi dan berdaya maju yang luas dalam melakukan suatu karya, (Kadjim 2011 : 10). Dengan kata lain, kerajinan adalah suatu kegiatan yang dilakukan secara terus menerus yang berkaitan dengan perbuatan tangan atau kegiatan tangan yang menghasilkan suatu karya. Kerajinan anyaman bambu adalah seni merajut yang biasanya menggunakan bahan dari bambu, rotan, daun-daunan yang memiliki serat yang dapat ditipiskan seperti enceng gondok, daun lontar, daun pandan, dan lain-lain, serta plastik. Kerajinan anyaman bambu banyak digunakan sebagai alat keperluan rumah tangga sehari-hari. Biasanya seni kerajinan anyaman bambu ini diolah dengan alat yang masih sederhana seperti pisau pemotong, pisau penipis, tang dan catut bersungut bundar, yang membutuhkan kreativitas tinggi, ide, perasaan, pemikiran dan kerajinan tangan.

Namun di sisi lain, terdapat permasalahan dalam mengembangkan UMKM kerajinan anyaman yaitu kurangnya keterampilan dan ketelatenan dalam membuat kerajinan anyman. Masyarakat Desa Sumberjo banyak yang berprofesi sebagai petani atau buruh tani. Demikian pula dengan pemuda Desa Sumberjo, mereka banyak memilih bekerja di luar kota. Hal ini dikarenakan kurangnya kesadaran masyarakat desa terhadap potensi yang dimiliki Desa Sumberjo yakni kerajinan anyaman. Mereka lebih banyak bekerja sebagai buruh 
pabrik dengan alasan pendapatan yang di terima relatif lebih tinggi daripada membuat kerajinan anyaman.

Buruh pabrik dan buruh tani/petani menjadi alternative pekerjaan yang mereka pilih karena dengan buruh pabrik atau buruh tani mereka cukup mengandalkan pekerjaan yang sekali selesai, beda dengan produksi kerajinan anyaman yang membutuhkan proses berkelanjutan. Perubahan cara pikir dan menjadikan ini sebuah budaya yang membuat mereka lebih memilih berprofesi sebagai buruh pabrik dan buruh tani/petani.

Berdasarkan latar belakang di atas, permasalahan yang diangkat adalah bagaiman pengembangan umkm kerajinan anyaman untuk meningkatkan perekonomian masyarakat desa sumberjo kecamatan sarirejo kabupaten lamongan. Tujuan yang ingin di capai adalah: (1) meningkatkan ketrampilan pengrajin anyaman dalam membuat produk anyaman bambu dan anyaman tikar; (2) meningkatkan daya saing produksi kerajinan anyaman, (3) meningkatkan perekonomian masyarakat Desa Sumberjo, Kecamatan Sarirejo, Kabupaten Lamongan melalui pembuatan laporan keuangan UMKM.

\section{METODE}

Penelitian ini menggunakan metode kualitatif yang ditekankan pada jenis deskriptif kualitatif. Teknik pengumpulan data yang digunakan adalah focus group discussion. Teknik ini digunakan untuk mengungkap pemaknaan dari suatu kalompok berdasarkan hasil diskusi yang terpusat pada suatu permasalahan tertentu. Objek penelitian merupakan sasaran untuk mendapatkan suatu data. Sugiyono (2014), menyatakan bahwa objek penelitian adalah suatu atribut atau sifat atau nilai dari orang, objek atau kegiatan yang mempunyai variasi tertentu yang ditetapkan oleh peneliti untuk dipelajari dan kemudian ditarik kesimpulannya. Objek penelitian dalam penelitian ini adalah UMKM kerajinan anyaman Desa Sumberjo, Kecamatan Sarirejo, Kabupaten Lamongan. Metode analisis yang di gunakan adalah analisis kualitatif dengan mendeskripsikan, menggambarkan serta menguraikan berbagai peristiwa yang terjadi dan di dapat dari informan melalui wawancara.

\section{HASIL DAN PEMBAHASAN}

Berdasarkan permasalahan di atas, untuk tujuan meningkatkan perekonomian masyarakat Desa Sumberjo Kecamatan Sarirejo Kabupaten Lamongan melalui pengembangan UMKM kerajinan anyaman terdiri dari tiga kegiatan yaitu: (1) Kegiatan koordinasi,singkronisasi jadwal,observasidanwawancara; (2) Pelatihan dan pengembangan UMKM kerajinan anyaman melalui pembuatan laporan keuangan; (3) Evaluasi kegiatan pengabdian masyarakat.

Pada kegiatan awal ini, koordinasi masih bersifat umum, belum ke teknis per kegiatan. Karena koordinasi teknis per kegiatan dilakukan setiap awal kegiatan pelatihan danpendampingan. Koordinasi awal ini mengarah pada kesepakatan umum tentang jadwal dan tempat pelatihan bertujuan agar pengrajin anyaman bisa hadir dan tidak berbenturan dengan kegiatan lain. Setelah melakukan koordinasi dengan pengrajin anyaman di Desa Sumberjo, langkah selanjutnya adalahmengajak para pengrajin anyaman untuk membuat sebuah paguyuban. Mereka diberikan pemahaman untuk bisa bekerja dalam sebuah sistem yang saling terintegrasi terutama aspek produksi dan pemasaran. Dengan adanya paguyuban mereka diharapkan bisa menghasilkan kualitas produksi yang sama baiknya dan dapat menyelesaikan segala bentuk masalah yang dihadapi. 


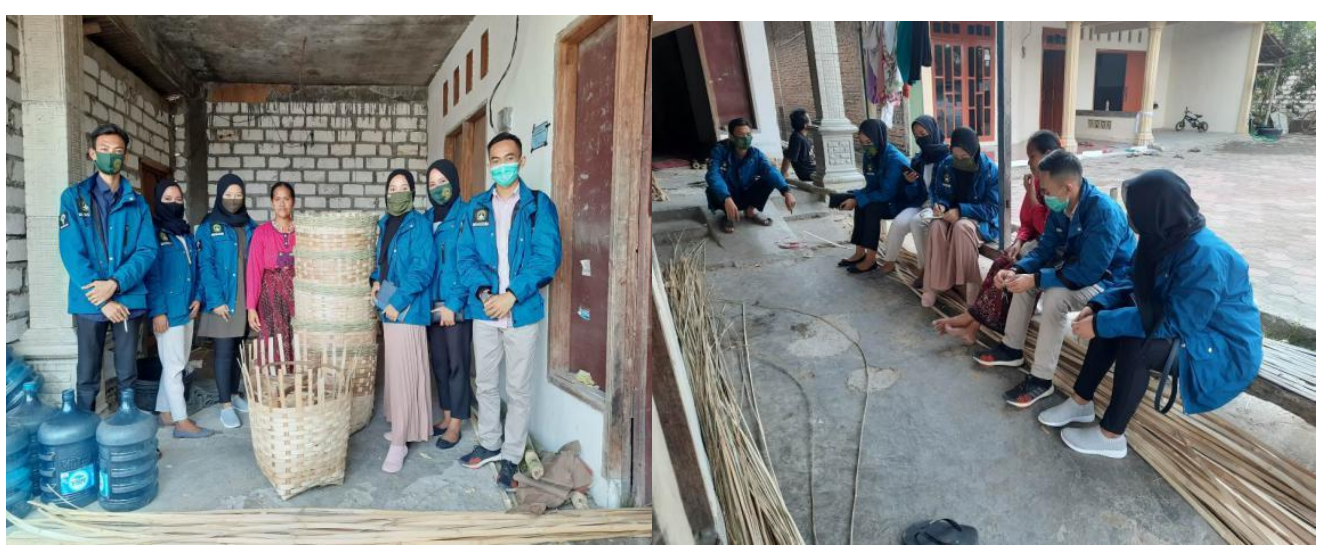

Kegiatan yang kedua adalah pelatihan dan pendampingan UMKM kerajinan anyaman. Hasilyangtelahdicapaidalampelaksanaanpelatihanpengembangan UMKM kerajinan anyaman yaitu (1) meningkatnyaketrampilan pengrajin anyaman dalam membuat produk anyaman bambu dan anyaman tikar; (2) meningkatnya daya saing produksi kerajinan anyaman; (3) meningkatnya perekonomian masyarakat Desa Sumberjo, Kecamatan Sarirejo, Kabupaten Lamongan melalui pembuatan laporan keuangan UMKM.

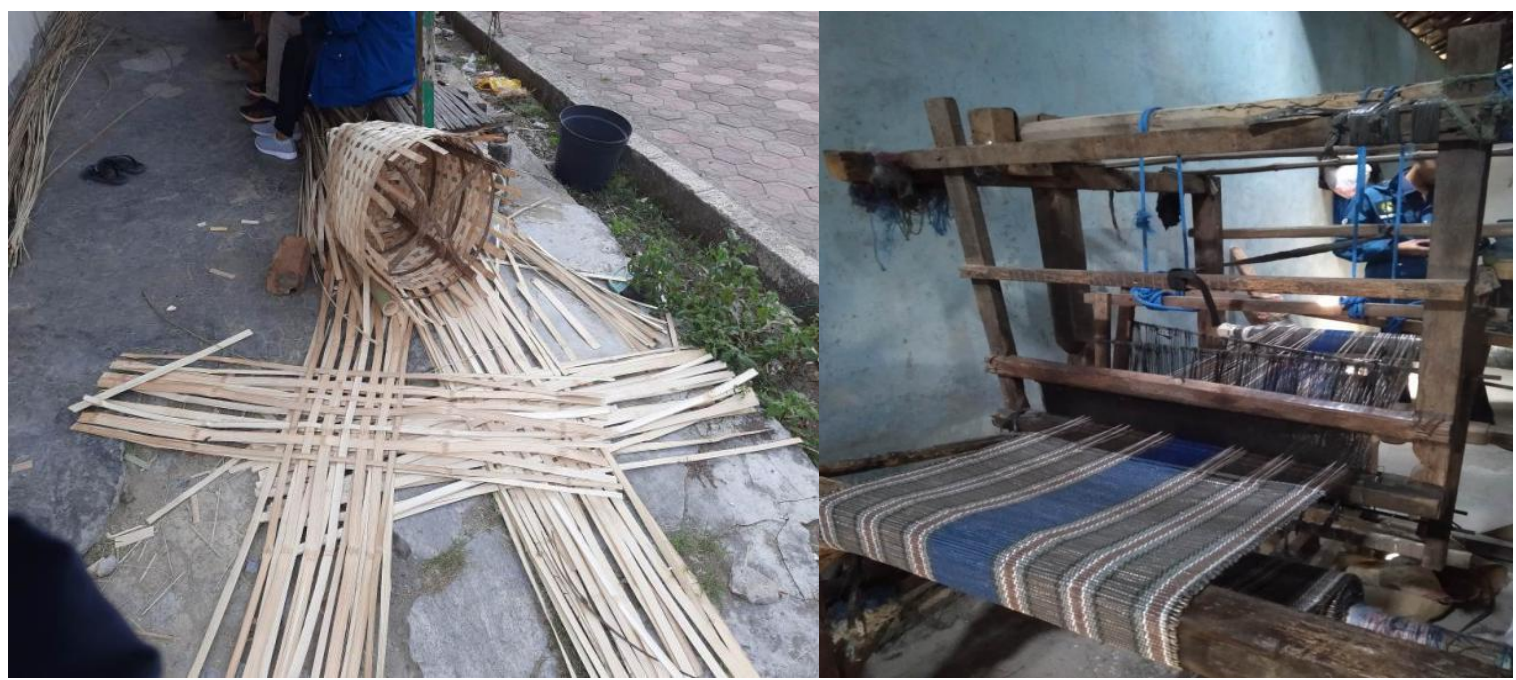

Kegiatan pelatihan dan pendampingan ini dilakukan dengan melibatkan dua orang dosen dan satu orang mahasiswa yang bermitra dengan pengrajin anyaman Desa Sumberjo, Kecamatan Sarirejo, Kabupaten Lamongan. Tim pengabdian dipilih berdasarkan bidang keahlian yang dimiliki sehingga dapat menunjang kegiatan Pengabdian Kepada Masyarakat (PKM).Sesuai dengan permintaan mitra,dimana kepala Desa Sumberjo menginginkan seluruh pengrajin dapat meningkatkan perekonomiannya, maka pelatihan ini melibatkan seluruh pengrajin anayaman yang berjumlah 20 orang. Teknis pelaksanaan dilakukan dengan metode pelatihan langsung. Pelaksanaan kegiatan pengabdian berlangsung selama 3 minggu.

Pada minngu terakhir, peserta pelatihan diminta untuk mengisi angket guna evaluasi kegiatan pelatihan dan pendampingan UMKM kerajinan anyaman. (Sugihartini, Agustini, \& Pradnyana, 2017). Dari hasil evaluasi oleh 20 peserta pelatihan, menunjukan $87 \%$ peserta pelatihan merasakan peningkatan ketrampilan pengrajin anyaman dalam membuat produk anyaman, $90 \%$ peserta merasakan peningkatan kemampuan pembuatan laporan keuangan 
UMKM, 88\% menyatakan dapat meningkatakan perekonomian masayrakat. Selain itu, 92\% peserta pelatihan menyatakan pelayanan tim sangat ramah dan melayani dengan baik, $98 \%$ peserta berharap pelaksanaan pelatihan berikutnya dapat dilakukan kembali, 85\% peserta menyatakan bahwa pelatihan sesuai dengan kebutuhan pengrajin anyaman Desa Sumberjo, 85\% peserta menyatakan pelatihan ketrampilan pengrajin anyaman melalui pengembangan UMKM dapat meningkatkan perekonomian masyrakat Desa Sumberjo.

\section{KESIMPULAN}

\section{Simpulan}

Kesimpulan yang diperoleh dari hasil kegiatan pengabdian masyarakat ini adalah bahwa masyarakat (Warga pengrajin kerajinan anyaman) di Desa Sumberjo, Kecamatan Sarirejo, Kabupaten Lamongan sangat tertarik dan termotivasi mengembangkan UMKM kerajinan anymaan untuk meningkatkan perekonomian masyarakat dengan dengan cara mengikuti sosialisasi dan pelatihan serta pendampingan peningkatan keterampilan pembuatan kerajinan anyaman, peningkatan daya saing produk dan pembuatan laporan keuangan.

\section{Saran}

Saran yang direkomendasikan bahwa agar kegiatan ini berkesinambungan yaitu untuk mengembangkan UMKM kerajinan anyaman di Desa Sumberjo, Kecamatan Sarirejo, Kabupaten Lamongan maka penelitian selanjutnya sebaiknya diarahkan pada teknik pemasaran produk yang lebih luas.

\section{DAFTAR PUSTAKA}

Erika Kusuma Yudha. 2017. Peningkatan Ekonomi Mastarakat melalui Usaha Kerajinan Tangan Anyaman Bambu di Desa Rimpak Kecamatan Sampuran, Kabupaten Wonosobo. Skripsi. Universitas Islam Negeri Sunan Kalijaga Yogyakarta.

Moelyono Mauled. 2010. Menggerakan Ekonomi Kreatif antara Tuntutan dan Kebutuhan. Jakarta: Rajawali Pers.

Peluangusaha.http://peluangusaha.co/rubrik/1276/Produk-Kreatif-Anyaman-BambuWonosobo-Terus-Menggeliat.html. diakses pada tanggal 2 Agustus 2020 pukul 14:08 WIB

Rhenald Kasali. 2010.Modul Kewirausahaan. Jakarta: PT Mizan Publika.

Syairozi, M. I., \& Susanti, I. (2018). Analisis Jumlah Pengangguran dan Ketenagakerjaan terhadap Keberadaan Usaha Mikro Kecil dan Menengah di Kabupaten Pasuruan. Jurnal Samudra Ekonomi dan Bisnis, 9(2), 198-208.

Sofjan Assauri. 2010.Manajemen Pemasaran. Jakarta: PT Rajagrafindo Persada.

Sugiyono. 2014. Metode Penelitian Kuantitatif Kualitatif dan R\&D. Bandung:Alfabeta.

Sumitro Djodjohadikusumo. 2014. Perkembangan Pemikiran Ekonomi Dasar Teori Ekonomi Pertumbuhan dan Ekonomi Pembangunan. Jakarta: LP3ES.

Widiastoeti, H., \& Sari, C. A. E. (2020). PENERAPAN LAPORAN KEUANGAN BERBASIS SAKEMKM TERHADAP KUALITAS LAPORAN KEUANGAN PADA UMKM KAMPUNG KUE DI RUNGKUT SURABAYA. JURNAL EKBIS: ANALISIS, PREDIKSI DAN INFORMASI, 21(1), 1-15. 